\title{
Enterprise Patent Control Ability (Concept, Attribute and Evaluation)
}

\author{
$\mathrm{Hu}$ Yunyin $^{1^{*}} \quad$ Amoah Nicholas ${ }^{2}$ \\ 1, 2.School of Economics and Management \\ Taizhou university Zhejiang province \\ 2.Zhejiang University of Science and Technology
}

\begin{abstract}
To explore and construct the theoretical system of research on the control ability of enterprise patent. [Method/process] Using the method of Literature research and survey, from the three dimensions of enterprise patent control technology, product and market to define the concept of enterprise patent control ability and set up the evaluation index system, analysis of the attributes of patent control ability of enterprise. Including dynamics, relativity, value and interest of two sides [Result/conclusion] the research results shows that the patent control ability of enterprise is to control core technologies through patent creation, application, protection, management and other activities, so as to control the supply and demand of specific products, ultimately affect and control specific competitors in specific regions, control industrial competition pattern and occupy the high end of the industrial value chain. Enterprise patent control ability is an important scale to evaluate the realistic status of enterprise and an important tool to predict the development trend of enterprise and industries.
\end{abstract}

Keywords: Patent technology, Patent products, Patent market.

DOI: $10.7176 / \mathrm{JESD} / 11-8-08$

Publication date: April $30^{\text {th }} 2020$

\section{Introduction}

Origin of the problem and Literature Review in June 2019, Huawei prepared to sue Verizon, a US operator that had long infringed its patents, for $\$ 1$ billion in royalties. Hearing the news, US Congressman Marco Rubio (Marco Rubio) tweeted: Huawei has become a patent troll. Chinese citizen have spoken one after another, isn't this a thief shouting to catch a thief? Because as we all know, the real "patent hooligan" is Qualcomm in the United States. Patent troll (patent troll) is also known as patent pirate (patent pirate), patent broker (patent brokering), patent ambush (patent ambush), patent bush (patent thicket), and generic subject (Non practicing entities). The issue of patent troll has always been controversial. Most scholars study its patent abuse and regulation from the perspective of jurisprudence. Few people stand in the perspective of management to interpret the normal driving patent behavior of those science and technology giants with legal knowledge. Today, in China, which is speeding up the implementation of the innovation-driven development strategy, on the one hand, Western multinationals often wave the big stick of "patented nuclear weapons" at Chinese enterprises, and often use patents for "nuclear blackmail." on the other hand, the western society is full of prejudice, discrimination and hostility to the rapid rise of China's patent dominant enterprises and the normal overseas protection of rights.

\section{Related Literatures}

\subsection{Study on Huawei and Verizon.}

The research on the patent control ability of enterprises is of great theoretical and practical significance to improve the patent application ability of Chinese enterprises, to enhance the ability of Chinese enterprises to deal with the patent abuse of multinational corporations, and to promote the overseas protection of rights and spirit of Chinese patent advantage enterprises. [1] Carried out the research on the evaluation index system and evaluation method of innovative enterprise strategic control ability. [2] Puts forward that the main elements of capital control ability of state-owned enterprises include occupation quality, technical quality and management quality. [3] Carried out fuzzy cluster analysis on the market control ability of shipping enterprises. [4] Answered the question of how to improve the cost control ability of high-tech enterprises. [5] Put forward the evaluation model of enterprise management control ability through theoretical analysis to verify the correlation between it and the application level of IT. [6] Developed an IC-CM model for evaluating the internal control capability of enterprises based on CMMI. [7] Empirically studied the influencing factors of risk control ability of financing guarantee enterprises. [8] Determine the evaluation index set of risk control ability based on enterprise management ability by functional analysis method, and subdivide the evaluation index set by the method of work breakdown structure, construct the evaluation model of construction risk control ability, and evaluate the construction risk control ability of construction enterprises with the help of fuzzy set theory. [9] Studied the financial risk control ability of new energy enterprises from the perspective of ecological civilization. [10] Puts forward the strategy of improving the financial risk control ability of real estate construction enterprises. [11] Discussed how to improve the safety control ability of high-risk operation in coal enterprises. 
The research of enterprise patent ability mainly includes the research of enterprise patent creation ability, enterprise patent management ability, enterprise patent financing ability and so on. Among them, [12] think about the cultivation of enterprise patent ability in the process of independent innovation. [13] Analyzes the interaction between enterprise patent ability and technological innovation. [14] Makes an empirical study on the influencing factors of enterprise patent ability. [15] Discussed the influence mechanism of enterprise patent competence on enterprise core competence. [16] Issued an appeal to enhance the independent patent creation ability of enterprises and change the weak position in the field of intellectual property rights. [17] Constructed the evaluation index system of enterprise patent creation ability. [18] Through the construction of "entrepreneur quality-organizational innovation atmosphere, organizational learning ability-employee innovation behavior" cross-level analysis model, this paper carries on the cross-level empirical analysis of the influencing factors of enterprise patent creation ability. [19] Empirically studied the influence mechanism of organizational innovation atmosphere on the patent creation ability of enterprises. [20] Studied the correlation between patent creation ability and performance of new third board enterprises and its influencing factors. [21] Thinks about the measures to improve the patent management ability of track equipment development enterprises. [22] Construct the evaluation index system of patent financing ability of high-tech enterprises from three angles: patent value, enterprise management status and external financing environment.

\section{The Policy}

\subsection{The National Intellectual Property Strategy of 2018.}

Since the promulgation and implementation of the outline of the National intellectual property Strategy in 2008, the CPC Central Committee and the State Council will implement the intellectual property strategy and establish the way to achieve the goal of building an innovative country into a well-off society in an all-round way. The report of the 19th CPC National Congress proposes to firmly implement the innovation-driven development strategy to enhance the driving force of China's sustainable development. On the road of innovation-driven development, patents drive technological innovation, technological innovation drives the development of enterprises, and enterprise development drives the optimization and upgrading of industry. The promotion of enterprise patent creation, application, protection and management ability appears frequently in the policy documents of party committees and governments at all levels, which not only shows that the concept of enterprise patent ability has entered the official discourse system, but also indicates that the research on enterprise patent control ability is carried out at the right time. As an academic term, enterprise patent control ability is formed by the organic combination of two different concepts: enterprise control ability and enterprise patent ability, but it is not a simple superposition or grafting of the two, nor is it a sub-concept of any of the concepts. Specifically. The patent control ability of enterprise refers to the ability of enterprise to control the corresponding products, markets and technologies through strategic actions such as patent creation, application, protection, application and social benefits of their innovative achievements are fully guaranteed in the process of innovation and development. The ultimate goal this research is to reveal the development direction of enterprise and industries. In order to gain a much understanding of the concept which is needed to comprehend. First of all, the enterprise patent control ability is a kind of comprehensive ability. Its constituent elements are divided into three aspects: the technical ability of enterprise patent control, the ability of enterprise patent control products, and the ability of enterprise patent control market. Enterprise patent control technology capability refers to the ability of enterprises to dominate and control the technology R \& D direction, technology evolution trend and technology life cycle by constructing patent network through the implementation of patent Portfolio strategy and patent M \& A strategy in a certain industry subdivision field.

Enterprise patent control product capacity refers to the ability of enterprises to continuously create, and protect basic patents and peripheral patents in a certain industrial subdivision field, so as to realized the width, length and correlation of a certain type of patent product portfolio. The life cycle of the product, the product jump, the product price and the sales income to exert influence The ability of enterprise patent control market refers to the ability of enterprises to continuously carry out strategic layout and strategic behavior, such as basic patent, peripheral patent, identical patent, standard basic patent, patent pool, patent litigation and so on, to create barriers to industrial entry, to achieve the absolute market share, the relative market share and the market growth rate, so as to build and consolidate the market leading position. In the field of titanium alloy super hard materials, multinational giants control the core technology through patent strategy, and then control the products and markets such as raw materials, products and downstream applications, and finally control the high end of the value chain of the industry.

Secondly, enterprise patent control is a kind of output control. The ability of enterprise patent control is not to control the enterprise patent itself, but to allocate and use patent resources through the creation, application, protection and management of enterprise patent, to exert influence and control on industrial technology, specific products and market structure. Enterprise strategic control, enterprise market control, enterprise financing risk control and enterprise material cost control are mostly a kind of input control. They correspond to the control of 
enterprise strategy, the control of enterprise market, the control of enterprise financing risk and the control of enterprise material cost. It can be said that the process of allocation of enterprise patent resources is also a process of gradually establishing the ability of enterprise patent control; the implementation of enterprise patent strategy is accelerated, the ability of enterprise patent creation, application, protection and management is gradually improved, and the ability of enterprise patent control is also enhanced; the transformation and upgrading of enterprise patent strategy, the ability of enterprise patent creation, application, protection and management is becoming more and more skilled, and the ability of enterprise patent control is becoming more and more powerful. To some extent, enterprise patent creation ability, enterprise patent application ability, enterprise patent protection ability and enterprise patent management ability are "cause", while enterprise patent control ability is "result". Finally, the evaluation of enterprise patent control ability should not only pay attention to the final control results, but also pay attention to the control behavior itself. When examining the patent control technology, products and market results of the research object enterprises, we should pay attention not only to the immediate results, but also to the medium-term results and long-term results. We should not only pay attention to the financial results such as cash flow, income and profit, but also pay attention to the non-financial results such as technological evolution, technological development trend, market entry barriers, industry competition structure and so on. When investigating the patent control technology, products and market behavior, we should not only pay attention to the normal driving patent behavior of the research object enterprises, but also pay attention to the patent abuse behavior of the research object enterprises. We should not only pay attention to the past patent control behavior of the research object enterprises, but also pay attention to the current patent control behavior of the research object enterprises. We should not only pay attention to the patent behavior of the object of study, but also pay attention to the patent behavior of other enterprises in the industry. Relativity. The relativity of enterprise patent control ability contains two meanings. First, the patent control ability will be different in the same industrial field and between different enterprises because of the difference in patent creation, application, protection and management ability. The patent technology output quantity is large, the quality is high, the distribution is dense and the commercialization degree is deep, the enterprise patent control technology, the product, the market ability is strong. Apple pays close attention to the patent layout in the field of human-computer interaction technology. Apple has the most patents in the fields of human-computer interface, touch control technology and so on. Multi-touch technology is almost perfect and has the best user experience design. Samsung has carried out a more stringent patent layout in the field of mobile communication systems, so the patent lawsuit filed by Samsung to Apple mainly focuses on data transmission methods and devices in mobile communication systems. Apple v. Samsung is mainly focused on gesture recognition technology. The patent battle between Apple and Samsung is essentially a tussle between the two giants over patent control. And vise versa. Second, the same enterprise may have different patent creation, application, protection and management capabilities in different industrial technology fields, and its patent control ability will also be different. In addition, industrial heterogeneity will also make a significant difference in the patent control ability of the same enterprise. Some industries are patent-intensive, some industries, such as the film industry, may be copyright-intensive, and some traditional manufacturing industries may be laborintensive or capital-intensive. There is no doubt that in a labor-intensive or capital-intensive industry, the reserve of enterprise patent knowledge is small, the depth, intensity and breadth of patent application and protection need to be strengthened, and the ability of patent control technology, products and market is relatively weak.

\section{Discussion}

\subsection{Hierarchy of Enterprise Patent Control Ability.}

Hierarchy. Enterprise patent control ability is first reflected in the control of technology, and then to achieve product control, the ultimate goal is to control the market, this control function is conductive. If the enterprise patent control ability is such as a network system, the enterprise patent control technology ability is in the innermost layer of the enterprise patent control ability network, and the enterprise patent control product ability is in the middle layer. And the enterprise patent control market ability is in the outermost layer. The hierarchy of enterprise patent control ability has a significant difference in the meaning of enterprise decision-making level, management layer and executive level. Obviously, different levels of managers have different requirements for patent control ability because of their different positions and different angles of thinking. The decision-making level is "strategically", grasps the enterprise long-term development strategy, pays more attention to the patent control technology ability; the executive level "leads the practice", implements the enterprise short-term concrete plan, pays more attention to the enterprise patent control product ability; the management is the "connection link" between the decision-making level and the executive level, is responsible for implementing the enterprise mediumterm development strategy, pays more attention to the enterprise patent control market ability. The technical ability of enterprise patent control has the guiding function, the market ability of enterprise patent control has the function of regulation and control, and the ability of enterprise patent control products has the function of developing. The study of enterprise patent control ability can be carried out from the three levels of technology, product and market, and the attribute characteristics of enterprise patent control ability should also be constructed from these three 
levels.

\subsection{Value of Enterprise Patent Control Ability.}

Value. As analyzed above, the enterprise patent control ability comes from the enterprise creation ability, the application ability, the protection ability and the management ability, is the organic integration and sublimation of these abilities. Enterprise patent control ability is an important support and guarantee of enterprise value creation ability, and has extremely important strategic value. Cultivating strong enterprise patent control ability requires enterprises to have strong capital reserve and human resource reserve, and more importantly, to have high quality patent reserve. Having strong enterprise patent control ability can bring lasting, stable and high economic return to the enterprise. Take Qualcomm Co., Ltd. As an example, on the one hand, Qualcomm Co., Ltd. has 118 core patents in 4G key technology field through patent application and patent acquisition, ranking first. At the same time, Qualcomm Co., Ltd. has ten to hundred core patents in this technology field, which continues to be far ahead of other competitors. On the other hand, Qualcomm Co., Ltd. and many well-known communications companies have a litigation relationship, they continue to compete for patent control in the field of technology. In addition, it has repeatedly raised objections in Europe to prevent competitors from obtaining patent licenses, or to narrow the scope of rival patent licenses. Qualcomm Co., Ltd. officially through the continuous implementation of patent control to create a "Qualcomm Kingdom." Qualcomm's chip and patent fees totaled \$24.3 billion in 2013, nearly half of which came from China, where licensing accounted for 30 per cent of revenue but accounted for 70 per cent of profits, twice as much as the chip business.

\subsection{The Right of Patent}

The two sides of rights and interests. As long as the enterprise owns and uses a certain number of patents and quality patents, it will gradually form a certain patent control ability. As mentioned above, the enterprise patent control ability is the organic integration and sublimation of all kinds of patent capabilities of the enterprise. However, the enterprise patent control ability is not linearly and positively related to the number of patents owned by the enterprise. The low patent control ability may make it difficult for the enterprise to survive and develop, and the strong patent control ability may bring lasting, stable and high economic return to the enterprise. As with the proper exercise of patent rights, the ability to control patents is not in itself an act of illegitimate domination. However, the abuse of patent rights to form a strong patent control ability, has produced a strong market dominance in the relevant markets, resulting in the exclusion and restriction of competition consequences, damage to social public interests or the interests of others is obviously illegitimate. It needs to be clear that when the enterprise patent control ability is strong, it is not necessarily the time for the enterprise to abuse the patent right. Therefore, we can say that the rights and interests of enterprise patent control ability have the dual characteristics of legitimate domination and illegitimate domination.

\subsection{The Elevation of Patent Index.}

The construction of the evaluation index system does not involve the problem of patent control in the current evaluation of enterprise control ability and the evaluation of enterprise patent ability, which cannot meet the requirements of improving the implementation level of enterprise patent strategy in the process of implementing innovation-driven development strategy. Nor does it fully reflect the improvement of the competitiveness of patent demonstration enterprises like Huawei. Many indicators of enterprise patent control ability are either not shown in the financial statements, or have not been systematically combed and summarized. Based on this, on the basis of following the principles of science, systematization and maneuverability, and from the three dimensions of product, market and technology, this paper constructs an evaluation index system of enterprise patent control ability, which is composed of three part first-level indexes, second-level indexes and third-level indexes, as shown in Table 1 on the other page.

4.4.1. Technical Capability of Patent Control.

It includes five secondary indicators, such as the technical orientation of the core in the same technical field, the proportion of the core applicant, the technical center of gravity index of the core applicant, the technology life cycle and the trend of technology evolution. Among them, the technical orientation of core applicants in the same technical field is usually divided into four types: technology pioneer type, independent development type, follower type and ephemeral type. It is mainly determined by four three-level indicators, such as the number of patents, the number of citations, the number of self-citations and the number of citations of others. The secondary indicators of the proportion of core applicants mainly include two level III indicators: the ratio of the number of core applicants to all applicants in the technical field, the number of patents owned by the core applicants and the number of patents owned by all applicants in the technical field. The core applicant's technical center of gravity index includes two tertiary indicators: the ratio of patent applications to all patent applications of core applicants in the same technical field in different IPC categories, and the ratio of the number of valid patents in different IPC categories to the number of all valid patents in the same technical field. The technology life cycle can be divided 
into five stages: the initial stage of technology, the stage of technological development, the stage of technological maturity, the stage of technological decline and the stage of technological redevelopment. The initial stage of technology refers to the stage in which the number of patent applications and patent applicants are small. The stage of technology development refers to the substantial increase in the number of patent applications and the increase in the number of applicants. The stage of technological maturity refers to the stage in which the number of patent applications is still increasing but the number of applicants remains unchanged, the stage of technology decline is the stage in which the number of patents remains unchanged and the number of applicants is greatly reduced, and the stage of technological redevelopment refers to the increase in both the number of patent applications and the number of patent applicants. The secondary index of technology life cycle is mainly reflected by the ratio of the added value of patent application to the added value of patent applicant. The secondary index of the trend of technological evolution is mainly reflected by the third-level index of the proportion of patent applications in each branch of IPC with the passage of time.

\subsubsection{The Ability of Patent Control Products.}

It mainly includes three secondary indicators: patent product portfolio, representative patent product sales price and profit, patent product jump and so on. Patent product portfolio is the realistic basis for the success of patent commercialization, including three third-level indicators: width, length and correlation of patent product portfolio, in which the width of patent product portfolio is not patent width (patent protection scope). It refers to the number of product lines owned by enterprises in the patent product portfolio in a certain industry subdivision field. The length of the patent product portfolio is also not the length of patent protection (the number of years the patent is protected by law), but refers to the total number of product items in an enterprise's patent product portfolio. The relevance of the patented product portfolio refers to the extent to which each patented product line is interrelated in terms of end-use, production conditions, distribution channels or other aspects. Take Apple as an example, its iPad products have launched iPad1,2,3, iPad Mini, iPad Pro, in which the iPad Pro screen is better, the processor is better, there are Smart Connector, support Pencil. In terms of the iPad Pro series, there are 9.7in, 10.5in, 11in and 12.9in models, while the Mac-book product line has 12-inch Mac-book and 13-inch, 15-inch Mac book Pro and Mac Mini;. The iPhone series, the iPhone product line, has 17 models: iPhone, iPhone 2G, iPhone 3G, iPhone 3GS, iPhone 4, iPhone 4s, iPhone 5, iPhone 5c and iPhone 5s, iPhone 6 and iPhone 6 Plus, iPhone $6 \mathrm{~s}$ and iPhone 6s Plus, iPhone SE, iPhone 7 and iPhone 7 Plus, iPhone 8 and iPhone 8 Plus, iPhone X, iPhone XR, iPhone and iPhone. The price and profit of representative patent products include three third-level indexes: sales price of representative patent products, sales profit of representative patent products and price elasticity of demand of representative patent products. The sales price of representative patented products and the sales profit of representative patented products can be measured by the price ratio and profit ratio of the same kind of nonpatented products, while the demand price elasticity of representative patented products mainly reflects the sensitivity of consumers to the price change of representative patented products. The jump of patent product mainly includes two three-level indexes: the implementation mode of patent product jump and the implementation effect of patent product jump. The jump of patent products, also known as patent product conversion, patent product substitution, product renewal or expansion, refers to the replacement of an innovation result for the expiring patent, so as to extend the market appeal of the original patent product. Take patented drugs as an example, the common forms of product jumps are (i) changing forms, such as from capsules and tablets to solutions; (ii) changing the molecular structure by adding or removing certain compounds; (3) repackaging two or more drugs sold separately in the form of compositions. There are two main ways to implement the jump of patented products: hard conversion and soft conversion. Among them, hard conversion mainly refers to the use of compulsory or similar coercive means in the process of implementing product conversion, while soft conversion does not use compulsory or similar coercive means. The implementation effect of patent product jump is mainly measured by comparing the changes of sales income before and after patent product jump.

4.4.3 The Ability of Patent Control Market.

It mainly includes three secondary indicators: the market share of patented products, the market growth rate of patented products and the barriers to market entry of patented products. Among them, the second-level index of patent product market share is further divided into two three-level indicators: absolute market share and relative market share. The secondary index of the market growth rate of patented products is further divided into two tertiary indicators: the growth rate of patented product sales and the growth rate of patented product sales. The barrier to market entry of patent products refers to the degree of advantage that patent advantage enterprises have for potential entry enterprises and new enterprises that have just entered the industry. The secondary index can be further subdivided into two three-level indicators: structural entry barrier and strategic entry barrier. The main factors that constitute the structural barriers to entry in the patented product market are the unique technical characteristics of the patented product, the difference between the patented product and the non-patented product, the unique preference of consumers for the function or appearance of the patented product, the network effect formed by more consumers and the amount of capital necessary for the production of this patented product (especially intellectual capital). The main factors that constitute the strategic barriers to entry into the patented 
product market are the patent layout and the improvement of the conversion cost of patented products.

Table 1: Evaluation Index System of Enterprise Patent Control Ability.

\begin{tabular}{|c|c|c|c|}
\hline $\begin{array}{l}\text { Level one } \\
\text { indicator }\end{array}$ & $\begin{array}{l}\text { Secondary } \\
\text { index }\end{array}$ & Third-level index & $\begin{array}{l}\text { Description of indicators } \\
\text { obtained }\end{array}$ \\
\hline $\begin{array}{l}\text { Patent Control } \\
\text { Technology } \\
\text { Capability }\end{array}$ & \multirow{4}{*}{$\begin{array}{l}\text { Core } \\
\text { applicant } \\
\text { Technology } \\
\text { positioning }\end{array}$} & Number of patents & $\begin{array}{l}\text { Patent Application Query } \\
\text { Web Search }\end{array}$ \\
\hline & & The number of citations & $\begin{array}{l}\text { Patent Application Query } \\
\text { Web Search }\end{array}$ \\
\hline & & The number of times of self-citation & $\begin{array}{l}\text { Patent Application Query } \\
\text { Web Search }\end{array}$ \\
\hline & & $\begin{array}{l}\text { The number of times of quote } \\
\text { others-citation }\end{array}$ & $\begin{array}{l}\text { Patent Application Query } \\
\text { Web Search }\end{array}$ \\
\hline & \multirow{2}{*}{$\begin{array}{l}\text { Proportion of } \\
\text { core } \\
\text { applicants in } \\
\text { the same } \\
\text { technical } \\
\text { field }\end{array}$} & $\begin{array}{l}\text { The ratio of the number of core } \\
\text { applicants to the number of all } \\
\text { applicants }\end{array}$ & $\begin{array}{l}\text { Patent Application Query } \\
\text { Net Search Calculation }\end{array}$ \\
\hline & & $\begin{array}{l}\text { The ratio of the number of patents } \\
\text { owned by the core applicant to } \\
\text { the number of patents owned by } \\
\text { all applicants }\end{array}$ & $\begin{array}{l}\text { Patent Application Query } \\
\text { Net Search Calculation }\end{array}$ \\
\hline & \multirow{2}{*}{$\begin{array}{l}\text { Core } \\
\text { applicant } \\
\text { Technical } \\
\text { Center of } \\
\text { Gravity } \\
\text { index }\end{array}$} & $\begin{array}{l}\text { The ratio of the number of patent } \\
\text { applications in different IPC } \\
\text { categories }\end{array}$ & $\begin{array}{l}\text { Patent Application Query } \\
\text { Net Search Calculation. }\end{array}$ \\
\hline & & $\begin{array}{l}\text { The ratio of the number of valid } \\
\text { patents to the number of all vaild } \\
\text { patents in different IPC } \\
\text { classifications }\end{array}$ & $\begin{array}{l}\text { Patent Application Query } \\
\text { Net Search Calculation }\end{array}$ \\
\hline & $\begin{array}{l}\text { Technology } \\
\text { life cycle }\end{array}$ & $\begin{array}{l}\text { The ratio of the added value of } \\
\text { patent applications to the added } \\
\text { value of patent applicants }\end{array}$ & $\begin{array}{l}\text { Patent Application Query } \\
\text { Net Search Calculation }\end{array}$ \\
\hline & $\begin{array}{l}\text { Technology } \\
\text { life cycle }\end{array}$ & $\begin{array}{l}\text { The proportion of IPC branch patent } \\
\text { applications increasing or } \\
\text { decreasing over time }\end{array}$ & $\begin{array}{l}\text { Patent Application Query } \\
\text { Net Search Calculation }\end{array}$ \\
\hline \multirow{6}{*}{$\begin{array}{l}\text { Patent Control } \\
\text { Product } \\
\text { Capability }\end{array}$} & \multirow[t]{3}{*}{$\begin{array}{l}\text { Patent } \\
\text { product } \\
\text { portfolio }\end{array}$} & Width & $\begin{array}{l}\text { Accumulative number of } \\
\text { research target enterprises } \\
\text { over the years }\end{array}$ \\
\hline & & Length & $\begin{array}{l}\text { Accumulative number of } \\
\text { research target enterprises } \\
\text { over the years }\end{array}$ \\
\hline & & Correlation degree & $\begin{array}{l}\text { Accumulative number of } \\
\text { research target enterprises } \\
\text { over the years }\end{array}$ \\
\hline & \multirow{3}{*}{$\begin{array}{l}\text { Sales price } \\
\text { and profit of } \\
\text { representative } \\
\text { patented } \\
\text { products }\end{array}$} & $\begin{array}{l}\text { Sales price of representative } \\
\text { patented products }\end{array}$ & $\begin{array}{l}\text { Accumulative number of } \\
\text { research target enterprises } \\
\text { over the years }\end{array}$ \\
\hline & & $\begin{array}{l}\text { Sales profit of representative } \\
\text { patented products }\end{array}$ & $\begin{array}{l}\text { Accumulative number of } \\
\text { research target enterprises } \\
\text { over the years }\end{array}$ \\
\hline & & $\begin{array}{l}\text { Demand price elasticity of } \\
\text { representative patented products }\end{array}$ & $\begin{array}{ll}\text { Market } & \text { Research } \\
\text { Calculations for } & \text { Patented } \\
\text { Products } & \\
\end{array}$ \\
\hline
\end{tabular}

\section{Conclusion and Prospect}

The patent control ability of enterprises is to realize the control of industrial technology, patent products and highend market through the implementation of strategies and tactics such as patent creation, application, protection and management. The enterprise patent control ability can be further subdivided into the enterprise patent control technology ability, the enterprise patent control product ability and the enterprise patent control market ability. To some extent, enterprise patent control technology is the starting point, control products is the means and methods, the ultimate goal is to control the high-end market, control the high end of the industrial value chain. Enterprise patent control ability is an important scale to evaluate the realistic status of enterprises, and it is also an important tool to predict the development trend of enterprises and industries. Through the analysis of enterprise patent control ability, we can predict the development trend of industrial technology, find the competitive situation of specific products, gain insight into the actual pattern of market competition, and reflect the future of industrial development. Although the argument of this paper is an incomplete argument, is a kind of exploratory research, but it is beneficial. In the future, the theoretical problems to be further studied on the patent control ability of enterprises may include: what is the formation mechanism of the patent control ability of enterprises? What is the transmission mechanism of enterprise patent control ability? How to choose the Scientific method for evaluating the Patent Control ability of Enterprises? On the other hand, the practical problems related to the research on the patent control ability of 
enterprises may include: how to correctly treat the technology giants with legal knowledge to exercise the patent control ability? How to guide Chinese high-tech enterprises to cultivate patent control ability? As well as the patent control ability of leading enterprises in patent-intensive industries is dynamically evaluated, and their abuse of patent control ability is examined and regulated in a timely manner.

\section{Reference.}

[1] Cao Xiaoli, Luo Jianqun, Chen Haisheng. Research on Index system and Evaluation method of Strategic Control capability of innovative Enterprises [J]. Friends of Accounting, 2009,4 (4): 9-12.

[2] Zhang Xinhua. Striving to improve the Capital Control ability of State-owned Enterprises [J] Journal of Economic Management, 1997, (5): 9-12.

[3] Gao Jie, Li Tao. Classification of Market Control capability of Shipping Enterprises, [J] containerization, 2004, (8): 42-46.

[4] Wang Dihua. How to improve the cost Control ability of High-tech Enterprises, [J] High Technology and industrialization, 2005, (2): 73-75.

[5] Peng Jianping, Lu Jingou. Evaluation of Enterprise Control capability and its impact on the Application level of IT [J] Science, Technology and Industry, 2008, (12): 38-44.

[6] Wang Hailin, Yang Zhounan. Research on the implementation Strategy of Enterprise Internal Control capability Evaluation Model [J] Financial Research, 2012, (8): 72-76.

[7] Xiao Zhi, Xia Shuang. Discussion on the influencing factors of risk Control ability of financing guarantee Enterprises, [J] Commercial economy Research, 2015, (6): 97-100.

[8] Sang Peidong, Li Xiangjun. Fuzzy set Evaluation of Construction Risk Control Ability. [J] Journal of Shandong University of Architecture, 2015, (6): 588594.

[9] Zheng Yuyu, Qiu Weilin. Research on Financial risk Control ability of New Energy Enterprises from the Perspective of Ecological Civilization, [J] Business Accounting, 2017, (22): 73-75.

[10] Lu Jian. Strategies for Improving the Financial Risk Control Ability of Real Estate Construction Enterprises, [J] Finance and Accounting Learning, 2019, (27): 28-30.

[11] Li Guowei. Discussion on Improving the Safety Control Ability of High Risk Operation in Coal Enterprises, [J] Shaan Xi Coal, 2019, (2): 183-185.

[12]Li Wei, Fan Lishu. Cultivation of Enterprise Patent Ability in the Process of Independent Innovation, [J] Scientific Research Management, 2010, (5): 73-75.

[14] Yang Jisheng. Analysis of the interaction between Enterprise Patent capability and technological Innovation, [C] Proceedings of the 2011 National Conference on Electronic Information Technology and Application, 2011: 963-966.

[13] Li Wei. Empirical study on influencing factors of Enterprise Patent capability, [J] Science of Science, 2011, (6): 84785.

[14] Li Wenli, Chen Jingyi, Wang Juan. Research on the influence Mechanism of Enterprise Patent competence on Core competence, [J] Industry and Science and Technology Forum, 2015, (16): 101-104

[15] Donggang. Enhancing the independent patent creation ability of enterprises to change the weak position in the field of intellectual property rights, [J] China economy and Trade, 2012, (2): 56-59.

[16]Yuan Lin, Qi Kai, Tan Wen. Cross-level Construction of Enterprise Patent creation ability Evaluation system, [J] Technical economy, 2014, (4): 28-32.

[17]Yuan Lin, Qi Kai, Tan Wen. Cross-level study on the influencing factors of Enterprise Patent creation ability, [J] Journal of University of Electronic Science and Technology, 2015, (6): 50-55.

[18]Yuan Lin, Tan Wen, Shao Yunfei. Research on the influence Mechanism of organizational Innovation atmosphere on Enterprise Patent creation ability, [J] Scientific Management Research, 2015, (9): 1-12.

[19] Luo Binyuan. Research on the correlation between Patent capability and performance of new third Board Enterprises and its influencing factors, [D] University of Electronic Science and Technology, 2017.

[20] Yang Yi River. Measures to Improve the Patent Management ability of Track Equipment Development Enterprises, [J] Technology and Market, 2015, (5): 223-224.

[21]Zhou Chaohui, Zhou Zhijuan. Construction and empirical study on Evaluation Model of Patent financing ability of High-tech Enterprises, [J] China Science and Technology Forum, 2019, (9): 56-66.

[22] Loasby, B. J (1998) , “The Concept of Capabilities”, in Foss, N. J. and Loasby, B. J. (eds.), Economic Organization, Capabilities and Co-ordination: Essays in Honour of G. B. Richardson, Ch. 9. London: Routledge. 